\title{
Hispanic Laborer is Crushed by Gantry Roller Press While Retrieving a Dropped Hammer
}

\author{
Incident Number: 14KY012
}

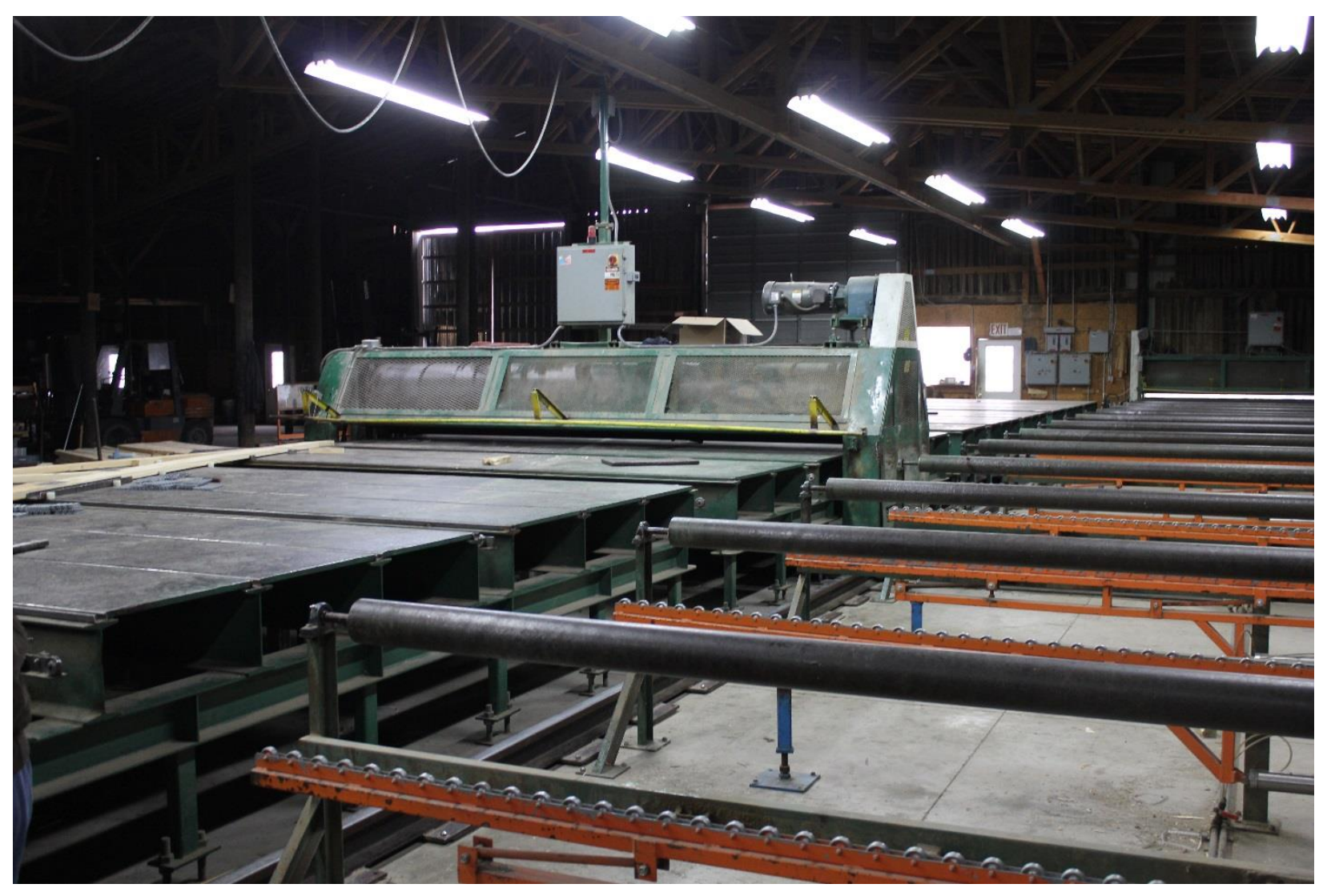

Kentucky Fatality Assessment and Control Evaluation Program Kentucky Injury Prevention and Research Center 333 Waller Avenue

Suite 242

Lexington, Kentucky 40504

Phone: 859-323-2981

Fax: 859-257-3909

www.kiprc.uky.edu

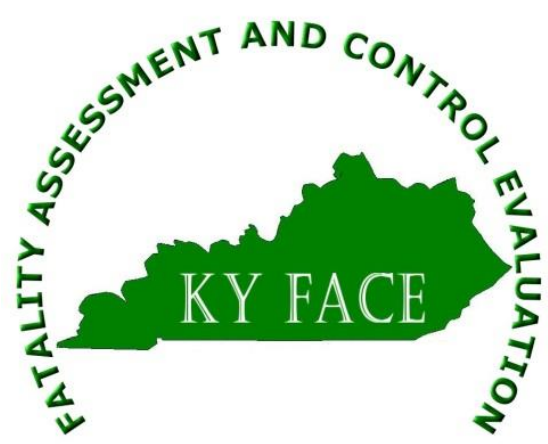


Kentucky Fatality Assessment and Control Evaluation (FACE) Program

Incident Number: 14KY012

Release Date: August 6, 2014

Subject: Hispanic Laborer is Crushed by Gantry Roller Press While

Retrieving a Dropped Hammer

\section{Introduction}

March 11, 2014 at 8:20 a.m. a 31- year- old Hispanic laborer working on a gantry roller press dropped a hammer he was using to tap the trusses into place. As the victim bent down to retrieve the hammer, the three other employees working with him did not see him and started the press. As the press came down the line, the victim raised up and became caught between the roller press and the legs of the press. This caused the press to jam. It wasn't until this occurred that the co-workers discovered the victim pinned by the roller carriage. The Sheriff stated that when he arrived, he found the victim face down with his legs over the guide-rail and his chest up against the table leg.

To prevent future occurrences of similar incidents, the following recommendations have been made:

Recommendation No. 1: Employees should ensure the work area is clear before operating moving equipment. Hazardous areas should also be marked clearly on the floor so employees are away from the danger zones when the press is in use.

Recommendation No. 2: Manufacturers should consider the redesign of the roller carriage guard to extend the guard and prevent the roller press from contacting employees or other objects in its path.

Recommendation No. 3: Manufacturers should consider the installation of light curtains to detect movement near the roller press before start up.

Recommendation No. 4: Manufacturers should consider the installation of an audible and visual warning device to provide sufficient work area clearance time before roller press operation commences.

\section{Employer}

The employer was a leading manufacturer and supplier of wood components for the construction industry. The business began in 1963 and has plants located in Ohio, Indiana, Missouri, Kentucky, Virginia, and South Carolina and services 20 states throughout the central and eastern United States. The employer also provides technical assistance on construction projects. There are 600 employees at the Kentucky location. 


\section{Written Safety Programs and Training}

At the time of the incident, the employer had the written safety programs in accordance with OSHA requirements. On-the-job training for the employees was performed through peer trainings, working alongside experienced co-workers.

\section{$\underline{\text { Victim }}$}

The victim was a 37- year- old Hispanic male from Mexico. He worked as a laborer on first shift in the manufacturing department. The victim had an education level of $8^{\text {th }}$ grade or less and had been hired 14 days prior to his death.

\section{$\underline{\text { Incident Scene }}$}

The scene was located in a manufacturing warehouse type structure. A gantry press which stretched from the front to the rear in an east to west direction was approximately 104 feet long by 20 feet wide by 15 feet tall. The roller followed a rail on both sides which was $2 \frac{5}{8}$ inches wide, with a 35 inch tall by $14 \frac{1}{2}$ foot wide by $103^{2} / 3$ feet long table which ran below the roller. Pneumatically lifted rollers were spaced equally, approximately every 80 inches along the table. The legs of the table had an opening between each leg of $17 \frac{1}{2}$ inches high and the opening between the legs spanned the length of the table and were 27 inches wide at the base plates and 31 inches wide between each leg. The guard observed was an interlock style that was operated by a bar that stretched the length of the roller carriage. The bar did not attach to the lower portion of the carriage. (See photo 1.)

\section{Weather}

Tuesday March 11, 2014 was a sunny day with temperatures ranging from 70 to 76 degrees Fahrenheit.

\section{$\underline{\text { Investigation }}$}

The Kentucky Fatality Assessment and Control Evaluation Program was notified of an occupational fatality involving a laborer by the Kentucky Labor Cabinet. An investigation into the fatality was opened and conducted.

The fatality occurred where employees assembled trusses on a gantry roller press. The employees assembled a truss on a specific jig on a 50 foot table. Depending on the size of the truss, usually, four (4) employees were used to assemble the truss, two (2) employees per side. Once the lumber was placed onto the table in the jig, the employees would attach plates at specified joints. When this task was completed, the employees exited the table. When activated, the roll press would roll over top of the plates setting them within the truss. The truss would then be lifted and placed on pneumatic rollers to the finish line. These steps would then be repeated. The two experienced employees, one with six (6) years' experience and the other employee with seven (7) years' experience were in charge of operating the press. The two less experienced employees, the victim who had been on the job fourteen (14) days and the other employee, with 
7 months experience, were on the opposite side of the press to help guide the trusses to the finish line.

The press was operated by a single control on the right side of the machine. The two (2) most experienced employees were the press operators and remained on the side with the controls. Standard operating procedure was to hand off the roller near the mid-point of the truss being created. The speed of the press was estimated by the Kentucky Compliance officer at $2.6 \mathrm{mph}$ or 3.8 feet per second. The press was a single speed press, not a variable speed, so the press could only run at this speed at all times.

The employees were in the process of setting a new truss onto the press. After setting the wood into place on the press table, the two press operators on the opposite side of the table did not see the victim and assumed he had walked off to use the restroom. The third employee on the same side of the press as the victim did not indicate there was an issue because he did not see the victim either. The press operator pushed the button, and the press was set into motion. As the press continued down in the direction of the victim, the victim raised up and was caught by the roller press and the legs of the press. The victim did not make a sound as the press caught him. It wasn't until the co-workers noticed the press stopped, that they discovered the victim between the roller press and the legs of the press. Immediately, the co-workers hit the emergency stop button and called their supervisor who contacted Emergency Medical Services.

The 911 call came into the call center at 8:25 a.m. CST and EMS was in route by 8:26 a.m. The caller reported a victim was down and he was not sure what had occurred. Another call came in to the 911 dispatch at 8:29 a.m. and the caller reported the victim was unresponsive, breathing, and they were not sure if he had been hit with a piece of machinery or had fallen. They just noticed he was down. At 8:33 the final call came into the 911 dispatch stating the victim was not breathing and had no pulse. The victim was on his face and his face was bleeding. Employees moved the victim and CPR was administered. EMS arrived at the scene at 8:38 a.m. The coroner arrived at the scene shortly after the EMS and pronounced the victim dead at the scene at 9:00 a.m.

While investigating the scene, the detective of the Sheriff's department and the coroner came to the conclusion the victim had dropped the hammer he had been using to set the trusses and had gone down to retrieve it. This placed the victim in the direct path of the rolling gantry press. A hammer was found alongside the victim which led to this conclusion. Witnesses could not confirm this conclusion since no one saw the victim prior to the incident, but there would have been no other reason for the victim to be in that area of the press.

\section{Cause of Death}

The cause of death was blunt force injuries from machine crush. 


\section{$\underline{\text { Recommendations and Discussions }}$}

Recommendation No. 1: Employers should ensure the work area is clear before operating moving equipment. Hazardous areas should also be marked clearly on the floor so employees are away from the danger zones when the press is in use.

The work area should always be confirmed clear before machinery is operated. Sight accountability of all employees working in the area should be maintained. Hazardous areas should also be properly labeled and identified to prevent injury; this will ensure employees are not in a hazardous zone.

Employees should stay aware of what the other members of the team are doing, and maintain communication at all times. This particularly applies each time the press is about to be activated.

Recommendation No. 2: Manufacturers should consider the redesign of the roller carriage guard to extend the guard and prevent the roller press from contacting employees or other objects in its path.

The interlock style guard that stretched the length of the roller carriage should be extended to stop the machine when it engages something in its travel path. An extended guard would have stopped the machine when it came into contact with the victim and shut off the machine. 29CRF 1910.212 (a)(1): Requires one or more methods of machine guarding to protect the operator and other employees in the machine area from hazards such as those created by point of operation, ingoing nip points, rotating parts, flying ships and sparks. Examples of guarding methods are barrier guards, two hand tripping devices, and electronic safety devices.

Recommendation No. 3: Manufacturers should consider the installation of light curtains to detect movement near the roller press before start up.

Manufacturers should install light curtains to detect movement near the machine before startup that will shut down equipment operation until reset, thereby minimizing the hazard of being caught by the machine.

Recommendation No. 4: Manufacturers should consider the installation of an audible warning device to provide sufficient work area clearance time before roller press operation commences.

Manufacturers should install an audible and visual warning device that alerts workers when the machine is started and allows them sufficient time to clear away from the equipment. A warning device such as a beeping buzzer might be installed. Since employees will be wearing hearing protection while working in this type of setting, a flashing strobe light would also be beneficial for those who may have hearing difficulties. 
Keywords

Trusses

Gantry Press

Caught between

\section{References}

https://www.osha.gov/pls/oshaweb/owadisp.show_document?p_table=standards\&p_id=9836

http://www.machineguardsolutions.com/howlightcurtainswork.html

http://www.grainger.com/category/audible-signaling-devices/safety-alarms-and-

warnings/safety/ecatalog/N-cck?cm_sa=true

http://www.federalsignal-indust.com/product/av1-led-flashing-combination-audiblevisual-signal

\section{Acknowledgements}

The Kentucky FACE program would like to thank the Kentucky Labor Cabinet and Kentucky OSHA, the Sheriff's department and the Coroner for their assistance with this report.

The Kentucky Fatality Assessment \& Control Evaluation Program (FACE) is funded by grant 2U60OH008483-10 from the Centers for Disease Control and Prevention and the National Institute for Occupational Safety and Health. The purpose of FACE is to aid in the research and prevention of occupational fatalities by evaluating events leading to, during, and after a work related fatality. Recommendations are made to help employers and employees have a safer work environment. For more information about FACE and KIPRC, please visit our website: www.kiprc.uky.edu 


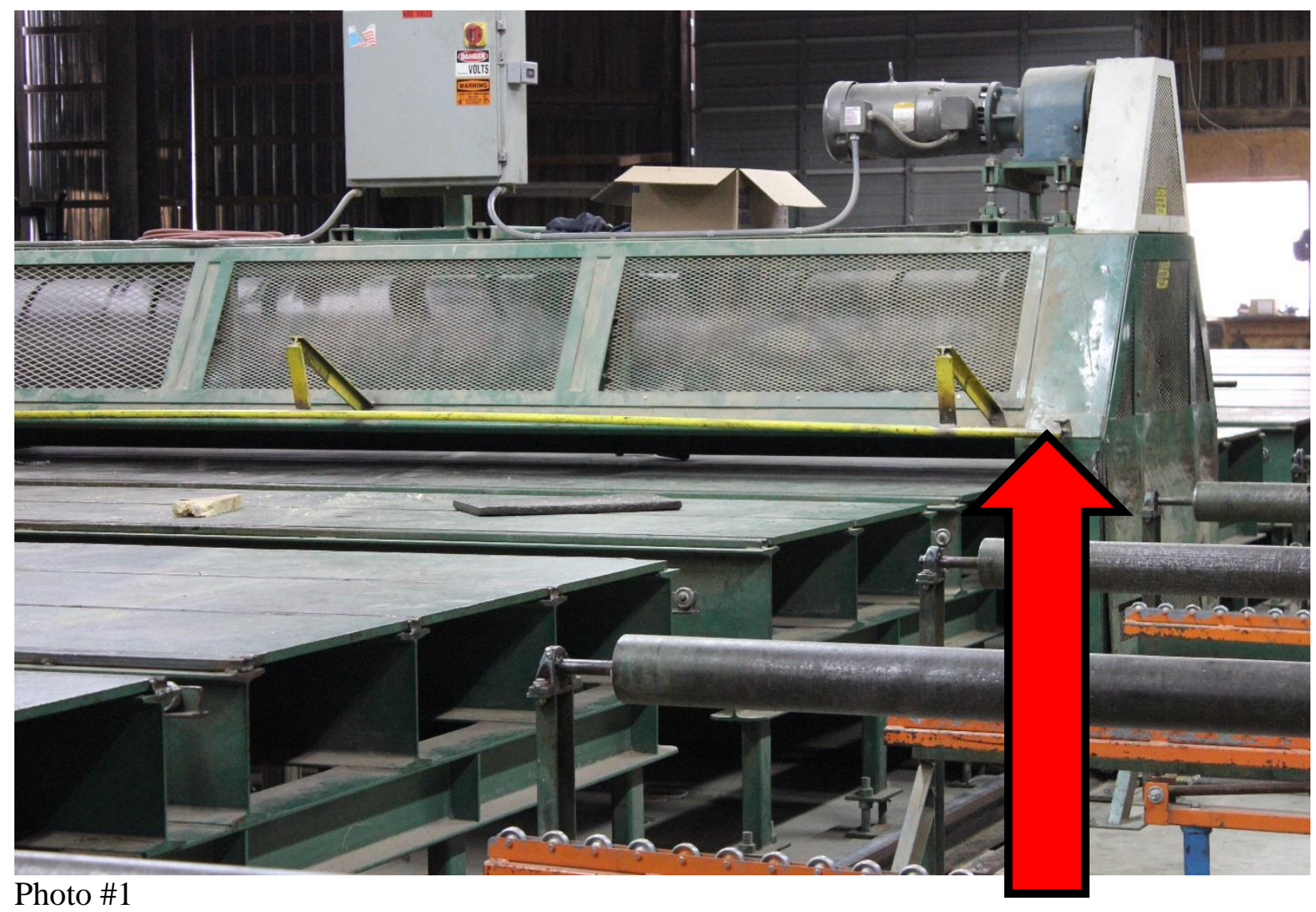

The arrow indicates the interlock, style guard and where the guard bar should be extended to stop equipment when it encounters interference while in motion. Photo courtesy of KY OSHA. 


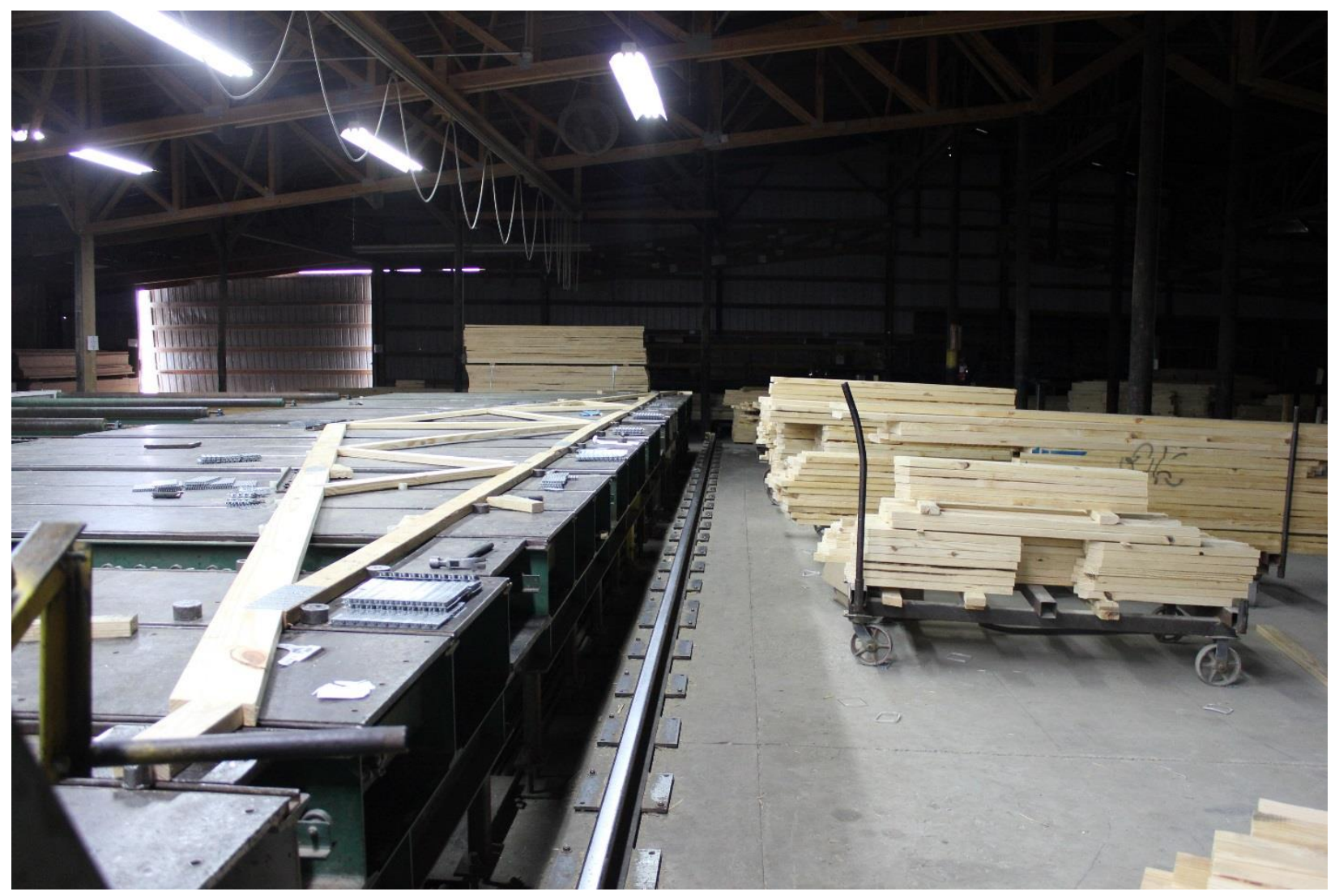

Photo \#2 shows the truss being built. Photo courtesy of KY OSHA. 


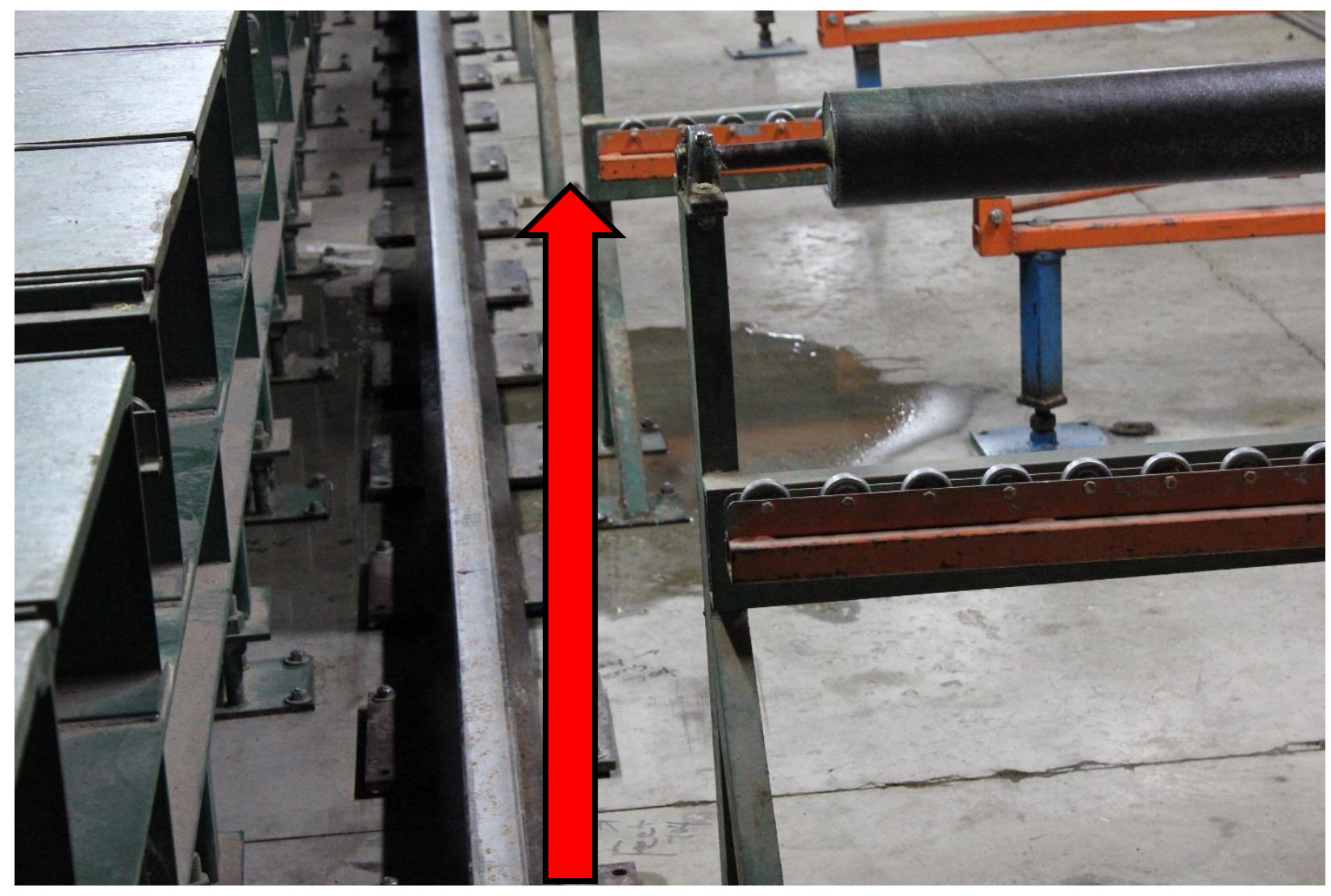

Photo \#3 shows the area where victim was crushed. Photo courtesy of KY OSHA 